\title{
Analgesic effects of ultrasound-guided Serratus anterior Plane Block after Video Assisted Thoracoscopic Surgery (VATS) Lobectomy : a comparative study
}

\author{
de la Caffiniere P, Bongarzone C, Olland A, Fischer F, Mertes PM, Steib A.
}

\section{BACKGROUND:}

Regional anesthesia contributes to early rehabilitation after video assisted thoracoscopic surgery (VATS) lobectomy, by decreasing postoperative pain and reducing morphine-induced adverse effects [1]. Several techniques may be used but there is no gold standard for VATS. Ultrasound-guided Serratus anterior plane block (SAPB) has recently been described for pain control after thoracotomy [2] or multiple ribs fractures [3]. We aimed to assess the effectiveness of SAPB associated to morphine patient controlled intravenous analgesia (PCIA) compared to PCIA alone on postoperative analgesia after VATS lobectomy.

\section{METHODS:}

This retrospective comparative study included the patients undergoing elective VATS lobectomy under minithoracotomy between January 2016 and May 2017. The patients were divided into two groups: SAPB group (ultra-sound guided SAPB + PCIA) and control group (PCIA alone). The primary objective was to assess cumulative morphine consumption during the first 24 postoperative hours. Secondary objectives included pain score (assessed at rest and cough), time to first analgesic request, duration of the recovery room stay and morphine-induced adverse effects (PONV, pruritus).

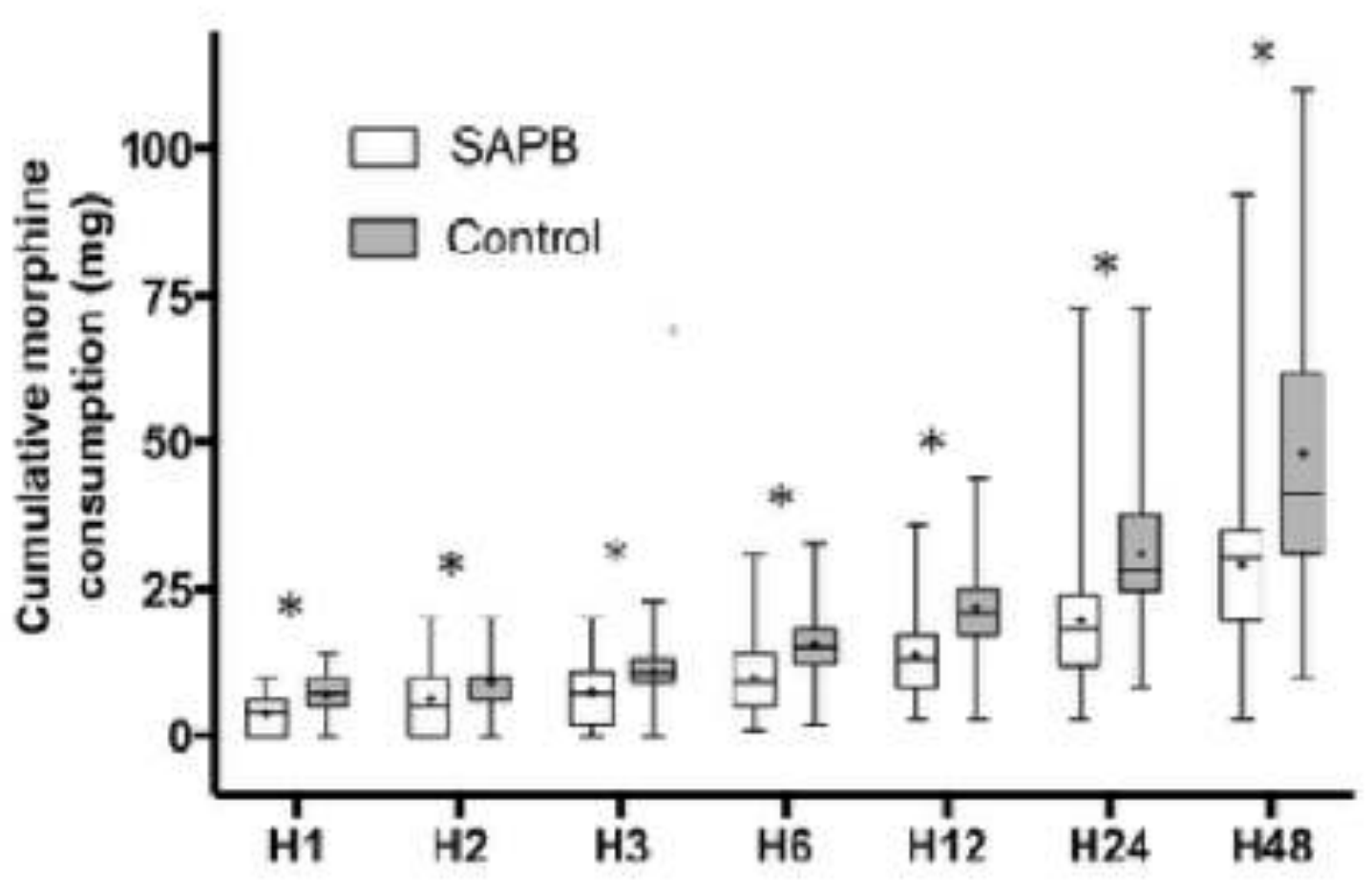

1. Wildgaard K, \& al, Eur J Cardio-thoracic Surg. 2012

2. Ökmen K \& al, J Anesth. 2017

3. Bossolasco \& al, J Clin Anesth. 2017

\section{RESULTS:}

Data from 129 were analyzed (SAPB group, $n=55$; control group, $n=74)$. The mean ( $\pm S D)$ cumulative morphine consumption during the first 24 postoperative hours was significantly lower in SAPB group (19.8 \pm 11.9 vs 31.0 $\pm 11.3 \mathrm{mg}, \quad P<0.0001$ ) [Fig1]. Postoperative VAS pain scores at rest were also found to be significantly lower in $S A P B$ group during the first 6 postoperative hours $(P<0.05)$ [Fig2]. SAPB prolonged median time to first analgesic request $[30 \mathrm{~min}(15-57.5)$ vs $10 \mathrm{~min}$ (5-20) in the PCIA group, $P=0.03$ ], but not the duration of stay in the recovery room. There were no significant difference concerning PONV and pruritus between the two groups.

\section{CONCLUSIONS:}

SAPB combined with morphine PCIA led to a reduction in total postoperative morphine consumption and provided better analgesia after VATS lobectomy during the first 6 postoperative hours compared to PCIA alone. The use of a catheter might contribute to prolong analgesia. Further prospective studies are therefore required.

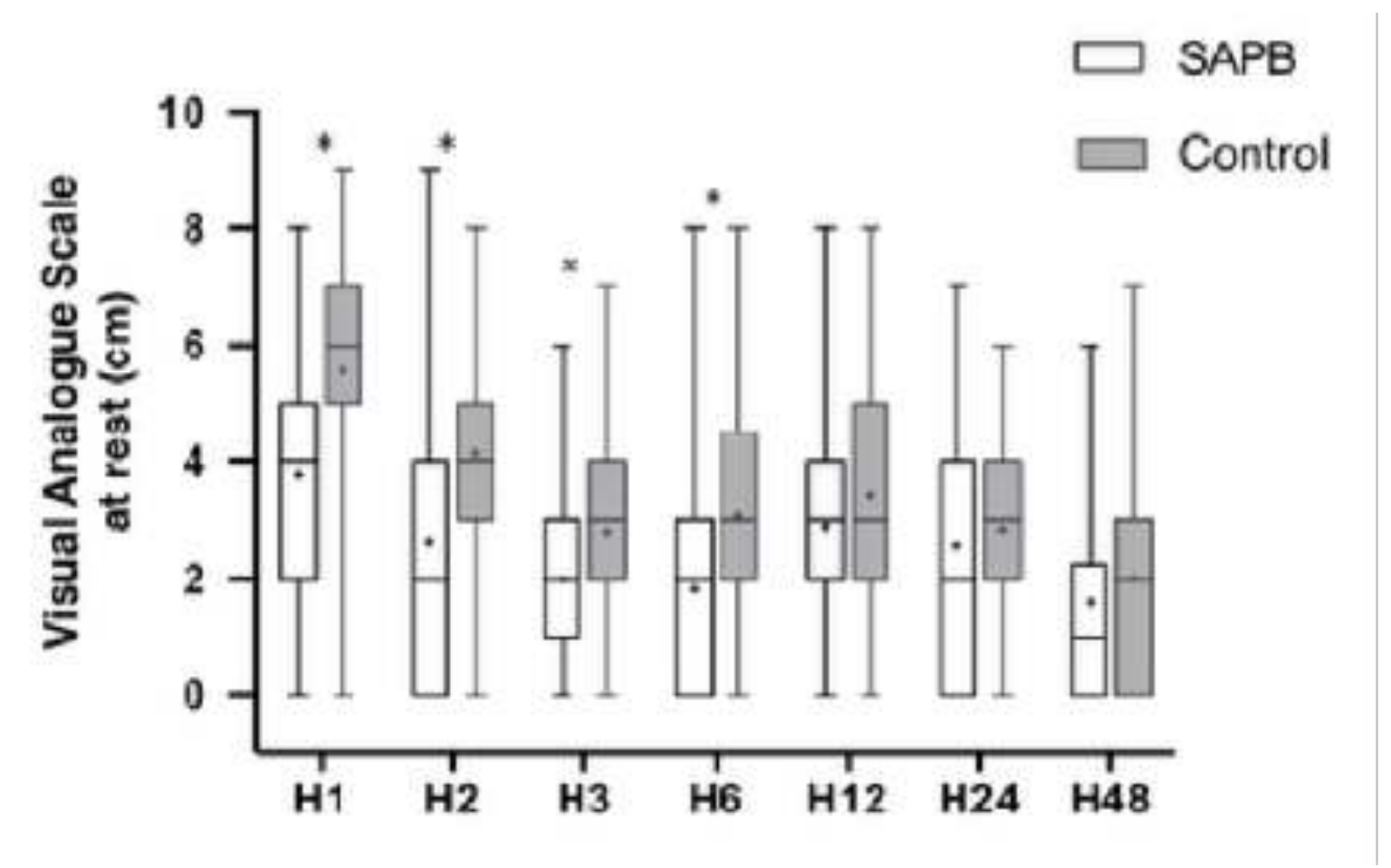

